\title{
Molecular Characterization of Virus Strain Causing Yellow Mosaic Disease (YMD) in Mungbean (Vigna radiata L. Wilczek)
}

\author{
Swapnil Shahakar*, Renuka and Anitha Pater \\ Department of Plant Biotechnology, University of Agricultural Sciences, GKVK, \\ Bengaluru-560065, Karnataka, India \\ *Corresponding author
}

\begin{abstract}
A B S T R A C T
Mungbean (Vigna radiata (L.) Wilczek) is a fast-growing warm-season legume, native to the Indian subcontinent; widely cultivated in Southeast Asia. It is an important pulse crop because of its short growth duration, low water requirement, and as a crop suitable for crop rotation and nutritional security being a rich source of protein. Biotic stress produced by viruses especially yellow mosaic virus (YMV) is the main constraint in its production causing substantial yield losses. The detection and diagnosis of viruses is most important to excogitate a management strategy. In this study coat protein gene was employed as a well characterized and widely used means for the identification as well as classification of different strains of YMV. Molecular characterization of YMV was done by using the coat protein (CP) gene of five isolates collected from Dharwad, Belgaum, Amravati, Gulbarga and Bengaluru to confirm their identity; isolates from Dharwad and Belgaum were classified as mungbean yellow mosaic India virus (MYMIV) and isolates from Amravati, Gulbarga and Bengaluru as mungbean yellow mosaic virus MYMV. Geographical confinement of species of YMV is validated; as MYMIV strain is more prevalent in northern, central and eastern regions of India whereas, MYMV is predominant in the southern regions.
\end{abstract}

Keywords

Mungbean, Mungbean yellow mosaic virus (MYMV), Mungbean yellow mosaic India virus (MYMIV), Coat protein, Phylogenetic analysis, Nucleotide sequence identity

Article Info

Accepted: 24 September 2018 Available Online: 10 October 2018

\section{Introduction}

Mungbean, Vigna radiata (L.) Wilczek, is one of the major legume crops cultivated in South East Asia, Indian, Southern Europe and also in Southern USA. High in protein content, low flatulence and easy to digest, mungbean consumption in combination with cereals can significantly increase the quality of protein in a meal (Thirumaran and Seralathan 1988). It is popularly grown as a component in inter cropping systems because of its ability to fix nitrogen, early maturity and relatively drought tolerance.
Plant virus diseases constrained the productivity of a wide range of economically important crops worldwide. Geminiviruses have ravaged large areas of crop plants mainly in tropical and subtropical countries (Banergee el al., 2018). Begomovirus, the largest genus of the Geminiviridae family containing small circular, single-strand DNA plant viruses having monopartite or bipartite (DNA-A and DNA-B) genome of approximately $2.7 \mathrm{~kb}$ size with $\sim 220$ bp common region (CR) (Kumar et al., 2017). 
The detection and diagnosis of viruses is most important to excogitate a management strategy. Molecular cloning and DNA sequencing of viral genomes have become imperative tools, admitting virus identification and establishing the relationships with other virus isolates (Manjunatha et al., 2001; Ha et al., 2008; Ramesh et al., 2017). In this study coat protein gene was employed as a well characterized and widely used means for the identification as well as classification of different strains of yellow mosaic virus (YMV). The coat protein encoded by begomoviruses act as protective coat and plays vital role in determination of transmissibility of the virus particle by whitefly (B. tabaci) vector. On account of highly conserved nature of coat protein (CP) gene among begomoviruses originating from the same geographical region, smaller fragments comprising the core CP gene, a partial 575579 bp sequence of the coat protein gene1 or the complete CP sequence have also been used to establish provisional species identification (Manjunatha et al., 2001).

Moreover complete genome sequences are expedient for identification and classification of geminiviruses, demands considerable efforts and expense. CP gene sequences are approved by the International Committee on the Taxonomy of Viruses (ICTV) for the provisional classification of begomoviruses when complete genome (monopartite virus) or A component (bipartite virus) sequences are inaccessible (Idris and Brown, 1998; Paximadis et al., 1998). The highly variable 50-200 nucleotides of the begomoviral $C P$ gene came up with as an informative region for anticipating taxonomic relationships within the genus Begomovirus (Mayo and Pringle 1998; Paximadis et al., 1995). The desirable sequence to be targeted for identification at both the species and strain/variant levels should contain both conserved and variable region (Brown et al., 2001).
Nucleotide sequence data of YMV genome component presently demonstrated four distinct bipartite begomoviruses as causal agent of yellow mosaic disease (YMD) of legumes in southern Asia (Qazi et al., 2007) which are collectively known as the mungbean yellow mosaic virus (MYMV), mungbean yellow mosaic India virus (MYMIV), horsegram yellow mosaic virus (HgYMV) and dolichos yellow mosaic virus (DoYMV) (Banergee et al., 2001).

Usually identification of particular strain of YMV affecting these crops is often ambiguous by simple morphological observations. Hence robust genomic approach should be implemented to detect the early infections in the crops. In order to implement better management strategy, present study was designed to identify different isolates of yellow mosaic virus affecting mungbean in Central and Southern part of India.

\section{Materials and Methods}

\section{Collection of virus isolates}

The MYMV virus isolates collected from the Department of Plant biotechnology, UAS, GKVK, Bengaluru as well as from Dharwad, Belgum and Gulbarga locations of Karnataka including one isolate from Amravati (Maharashtra) were used for molecular characterization.

\section{DNA extraction and amplification MYMV CP gene}

Young leaves showing the characteristic yellow mosaic symptoms were used for DNA isolation. DNA was isolated from virus infected leaves $(100 \mathrm{mg})$ by following the protocol of Shahakar and Peter (2015). The quality and yield of extracted DNA were determined by agarose gel electrophoresis and spectrometric analysis. The total DNA 
obtained was used as a template to amplify the coat protein gene AV1, using the gene specific primers in a polymerase chain reaction (PCR).

The amplification was performed in a Thermocycler, Biometra ${ }^{\circledR}$ (Goettingen, Germany).

Isolated DNA samples were subjected to PCR using CP gene specific primers (MYMV cpFwd: 5' ACA CGA GCT CCT CTA CCC CGA TAT CGA ATG 3' and MYMV cpRev: 5' ACA CGG ATC CGT TGC ATA CAC AGG ATT TG 3') (Islam et al.,2012) following an initial denaturation at $95^{\circ} \mathrm{C}$ for 5 minutes and 40 cycles of denaturation at $94^{\circ} \mathrm{C}$ for 45 second annealing at $60^{\circ} \mathrm{C}$ for 50 second, extension at $72^{\circ} \mathrm{C}$ for 1 minute and reaction was completed with final extension at $72^{\circ} \mathrm{C}$ for 15 minutes.

PCR amplicons were separated by agarose gel (1.2 per cent) electrophoresis in Tris-acetate EDTA (TAE) buffer and amplification was confirmed.

\section{Cloning of amplified MYMV CP gene into E. coli}

The amplified product was eluted from gel on a low intensity UV transilluminator by using Fermentas GeneJET gel extraction kit (\#K0691) and collected in sterile pre-weighed $2.0 \mathrm{ml}$ micro centrifuge tubes.

The purified PCR fragment of about $\sim 730 \mathrm{bp}$ was separately ligated to pTZ57R/T cloning vector (2886 bp). Ligation was performed in the molar ratio 3:1 of insert and vector using T4 DNA ligase as described in InsTAclone ${ }^{\mathrm{TM}}$ PCR cloning kit, Fermentas, USA.

Transformation and confirmation of recombinant colonies

The competent cells of E. coli DH5 $\alpha$ were prepared following the standard protocol mentioned in InsTAclone ${ }^{\mathrm{TM}}$ PCR cloning kit, Fermentas, USA. An isolated colony from $E$. coli DH5 $\alpha$ plate was inoculated into $5 \mathrm{~mL}$ of Luria broth and incubated at $37^{\circ} \mathrm{C}$ overnight at $180 \mathrm{rpm}$. The next day, $10 \mu \mathrm{l}$ culture was inoculated in $1.5 \mathrm{ml} \mathrm{C}$-medium provided with kit. It was incubated for 2-3 hours till it attained an OD of 0.3 to 0.4 at $600 \mathrm{~nm}$ and competent cells were prepared according to the instruction given in protocol.

Transformation of competent E. coli DH5 $\alpha$ was done using same kit as mentioned above. The prepared competent cells were used for transformation with recombinant pTZ57R/T carrying MYMV-CP gene insert. Tube containing ligation mixture (pTZ57R/T + MYMV-CP gene) about $2.5 \mu \mathrm{l}$ was chilled on ice for $2 \mathrm{~min}$, then added with $50 \mu \mathrm{l}$ of the competent cells, mixed and incubated on ice for $5 \mathrm{~min}$. The cells were then immediately plated on pre-warmed LB-ampicillin XGal+IPTG agar plates, incubated overnight at $37{ }^{\circ} \mathrm{C}$ and growth of cells was observed. The recombinant clones were identified by bluewhite colony screening.

\section{Colony PCR for confirmation of transformed cells}

The suspected transformants which appeared as white colored colonies as well as blue colonies were picked from the plate and used in colony PCR as template with PCR conditions same as used for MYMV CP gene amplification. Template for reaction mixture was prepared by diluting single transformed white colony in $20 \mu \mathrm{l}$ sterile double distilled water. The components of reaction mixture were as 10X PCR buffer with $15 \mathrm{mM} \mathrm{MgCl} 2$ $2 \mu \mathrm{l}, 2 \mathrm{mM}$ dNTPs- $2 \mu \mathrm{l}$, forward and reverse primer $\quad(10 \quad \mathrm{pmol} / \mu \mathrm{l})-1 \quad \mu \mathrm{l}, \quad$ Taq DNA polymerase- $1 \mu \mathrm{l}$, and template DNA (50-60 ng)-1 $\mu$ l. The cells were mixed thoroughly in PCR reaction mixture as mixing resulted in 
complete cell lysis. Amplified DNA fragments were resolved on 1.2 per cent $(\mathrm{w} / \mathrm{v})$ agarose gel.

\section{Confirmation of recombinant vector for MYMV CP gene}

The confirmation of recombinant vector was done by isolating plasmid DNA from bacterial white colonies and amplification of desired CP gene sequence. Plasmid DNA was isolated following the alkaline lysis protocol (Brimbion and Dolly, 1979). MYMV CP gene sequence was amplified from recombinant plasmid vector using M13 forward and reverse primers. The binding site for M13 primers was present in the vector pTZ57R/T which amplifies the $\mathrm{CP}$ gene sequence with additional $\sim 200$ nucleotide sequence from vector and band corresponding to size of amplified sequence was made confirmed by resolving it on 1.2 per cent agarose gel with 1 kb plus DNA ladder (75bp-2000bp).

\section{Sequencing of cloned $\mathrm{CP}$ gene}

The MYMV CP gene cloned into pTZ57R/T was sequenced using gene specific primers for Gulbarga isolate and M13 primers for Dharwad, Belgaum, and Bengaluru isolate at AgriGenome Pvt. Ltd., Bengaluru.

\section{Homology search and Bioinformatics study}

Forward and reverse sequence of MYMV CP gene obtained after sequencing for each strain are joined as single sequence by using BioEdit CAP contig assembly program and exact gene specific primer amplified product was trimmed by using SnapGene program. The nucleotide sequence of MYMV CP was submitted to the BLAST (Basic Local Alignment Search Tool) search at NCBI server (http://www.ncbi.nlm.nih.gov/blast/) to find out sequence identities with deposited YMV CP gene sequence in the GenBank. The
$\mathrm{CP}$ gene sequences from present study were used for homology study and phylogenetic analysis with 24 different $\mathrm{CP}$ gene sequences downloaded from NCBI. To study the sequence homology, multiple sequence alignments were performed for all $29 \mathrm{CP}$ gene sequence (5 present study isolate, 24 isolates from NCBI including both MYMV and MYMIV strain) by ClustalW2 multiple sequence alignment program associated with BioEdit. Pair wise percent identities present among sequences were estimated by SDTv1.2 program. Phylogenetic analyses for 29 sequences were conducted using MEGA7 (Molecular Evolutionary Genetics Analysis 7) program with Bootstrap value of 1500 replications to estimate the confidence of branching patterns for UPGMA phylogenetic tree.

\section{Results and Discussion}

\section{Molecular characterization of YMV isolates of mungbean}

\section{DNA isolation}

DNA extraction was done by following the protocol of Shahakar and Peter (2015). DNA quality and yield was estimated by gel electrophoresis $(0.8 \%)$ and checking OD in biospectrometer respectively which was $\sim 800$ $\mathrm{ng} / \mu \mathrm{l}$ with absorbance ratio $\left(\mathrm{A}_{260} / \mathrm{A}_{280}\right)$ of 1.82 to 1.89 indicating very low level of protein and RNA contamination (Burden and Whitney, 1995).

\section{PCR amplification of coat protein gene}

YMV CP gene was amplified by PCR using gene specific primer and amplified product was confirmed by agarose gel electrophoresis for a band size of $\sim 730$ bp with reference DNA ladder (Fig. 1). The amplified product was extracted from agarose gel, ligated to the vector $\mathrm{pTZ57R/T}$ and further used for cloning. 
Transformation of $E$. coli strain DH5a with recombinant vector $\mathrm{pTZ57R/T}$

The amplified YMV-CP gene after elution from agarose gel ligated to vector $\mathrm{pTZ}$ 757R/T and cloned into E.coli strain DH5a. Transformed cells were selected from the cultured plates based on blue/white colony screening and white colonies were considered as a transformed (Fig. 2).

The principle behind the selection of white colonies as transformed is insertional inactivation of $\beta$ galactosidase gene because of insert sequence which made it unable to encode active enzyme necessary for cleavage of substrate X-Gal and production of blue colored colonies.

\section{Confirmation of recombinant clone by colony PCR}

Transformed E. coli colonies were confirmed through colony PCR with gene specific primers. Both blue and white colonies were made to amplify $\mathrm{CP}$ gene, only white colonies gave amplification specific to the $\mathrm{CP}$ gene size and blue colonies did not give any amplification (Fig. 3). Transformed cells with recombinant plasmid were further confirmed by isolation of plasmid pTZ57R/T and amplification of $~ 930 \mathrm{bp}$ bands by using M13 primer (Fig. 4)

\section{Sequencing of YMV-CP gene sequences} and homology study

The identity of YMV CP gene was confirmed by sequencing the amplified product from the five YMV isolates at AgriGenome research Technology Pvt. Ltd., Bengaluru.

\section{Sequence analysis of coat protein gene}

The single joined sequence obtained from BioEdit CAP contig assembly program and after trimmed by SnapGene program was 722 bp for each isolate from Dharwad, Belgaum, Amravati, Gulbarga, and Bengaluru.

The result of BLAST analysis for each isolates was depicted in Fig. 5. The isolate from Belgaum (Karnataka) (722 bp) and Dharwad (Karnataka) (722 bp) having almost identical CP gene sequence and showed 98-99 per cent nucleotide identity with different isolates of MYMIV and produced a significant alignment with an E-value of zero "0.0" (Fig 7).

Both isolates showed 99 per cent sequence identity and query coverage of 97 per cent (E value 0.0) with mungbean yellow mosaic India virus isolate MYMIV-Mb01 coat protein (AV1) gene, (complete cds, GQ387501.1) from Bhopal (LC271792.1), Jabalpur (LC271790.1), Palampur (FN794200.1) and one MYMIV soyabean isolate (AJ416349.1).

The isolate from Amravati (Maharashtra) (722 bp) showed 97-98 per cent nucleotide identity with different isolates of MYMV and produced a significant alignment with an Evalue of zero " 0.0 " (Fig 7). It showed 98 per cent sequence identity with 97 per cent query coverage to the different isolates namely mungbean yellow mosaic virus clone VA1 segment DNA-A, complete sequence (KC911722.1), mungbean yellow mosaic virus-Vigna (Maharashtra) A component, complete sequence (AF314530.1), mungbean yellow mosaic virus-Thailand DNA A, complete sequence (AB017341.1), and mungbean yellow mosaic virus-Soybean (Madurai) segment DNA A, complete sequence, strain Madurai (AJ421642.1)

Gulbarga (Karnataka) (722bp) isolates showed 99 per cent nucleotide identity with mostly MYMV strain except one MYIMV strain producing a significant alignment with an Evalue of zero " 0.0 ". Gulbarga isolate showed 99 per cent sequence identity with 99 per cent query coverage to the different isolates as 
mungbean yellow mosaic India virus pre-coat protein (AV2) and coat protein (AV1) genes, complete cds (DQ389150.1), Mungbean yellow mosaic virus-Vigna (Maharashtra) A component, complete sequence (AF314530.1), Mungbean yellow mosaic virus-Thailand DNA A, complete sequence (AB017341.1), Mungbean yellow mosaic virus isolate Namakkal segment DNA-A, complete sequence (DQ865201.1), and Mungbean yellow mosaic virus-Soybean (Madurai) segment DNA A, complete sequence, strain Madurai (AJ421642.1)

The isolate from Bengaluru (Karnataka) (722bp) showed 98 per cent nucleotide identity with different isolates of MYMV and produced a significant alignment with an Evalue of zero " 0.0 " (Fig 7). This isolate showed 98 per cent sequence identity with 97 per cent query coverage to the different isolates as mungbean yellow mosaic virusVigna (Maharashtra) A component, complete sequence (AF314530.1), Mungbean yellow mosaic virus isolate Namakkal segment DNAA, complete sequence (DQ865201.1), Mungbean yellow mosaic virus-Soybean (Madurai) segment DNA A, complete sequence, strain Madurai (AJ421642.1), mungbean yellow mosaic virus isolate Green AV1-like gene, complete sequence (KY824800.1) and mungbean yellow mosaic virus-Vigna segment $\mathrm{A}$, complete sequence (AJ132575.1).

Multiple sequence alignment were performed for YMV CP gene sequence of 29 isolates (5 present study isolate, 24 isolates from NCBI including both MYMV and MYMIV strain) by ClustalW2 multiple sequence alignment program is depicted in Fig. 6.

Fig.1 Ethidium bromide stained agarose gel showing amplification of YMV CP gene using genespecific primers

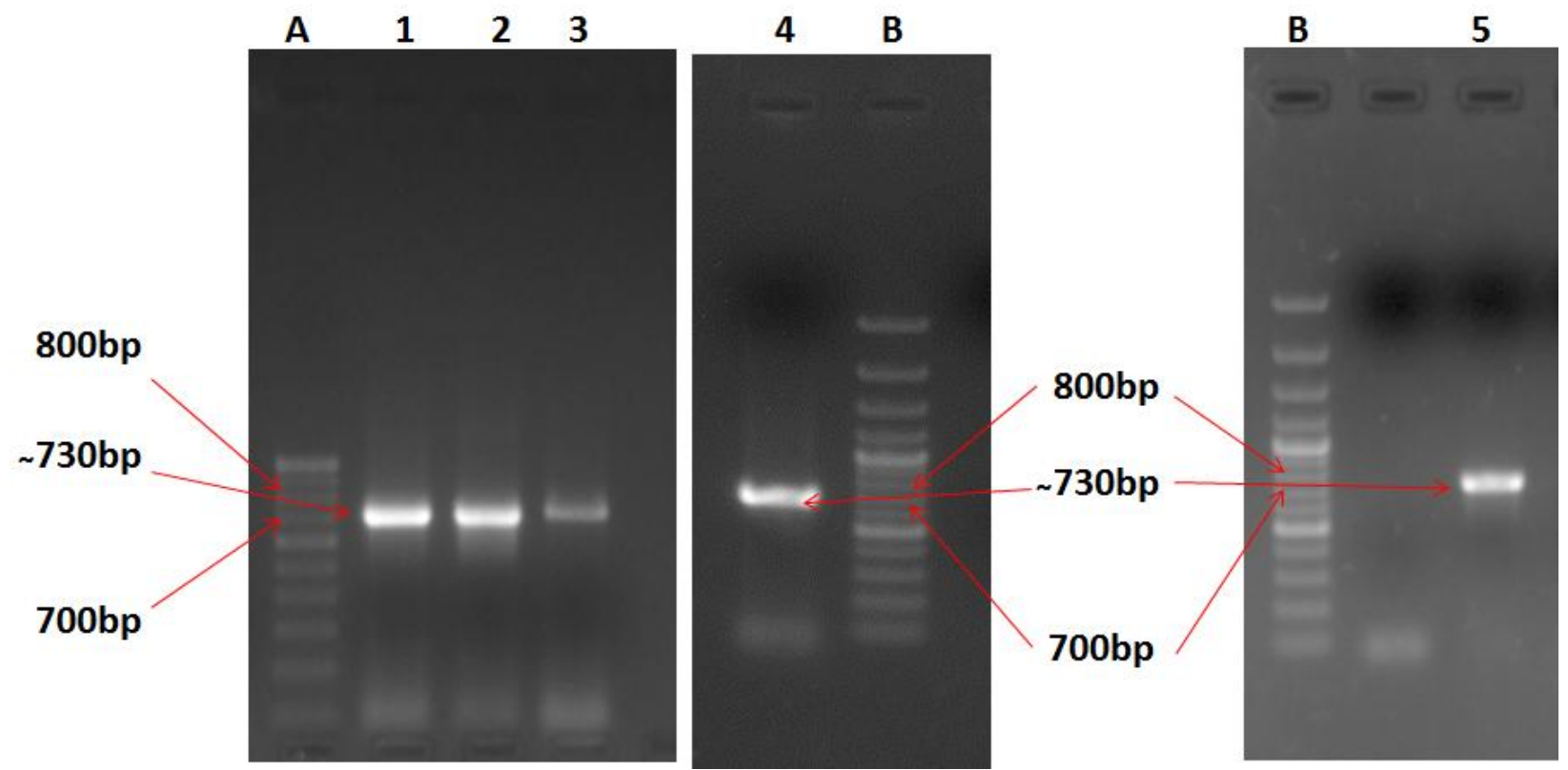

A-100bp DNA ladder (100bp-1000bp), B-100bp DNA ladder (100-3000bp), 1-Dharwad isolate, 2- Belgaum isolates, 3-Amravati isolate, 4- Gulbarga isolate and 5-Bengaluru isolate 
Fig.2 Blue white colonies of E. coli strain DH5aon Luria-Bertani agar/ampicillin/X-gal/IPTG

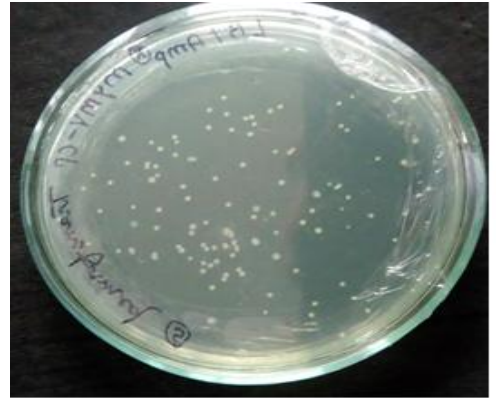

A

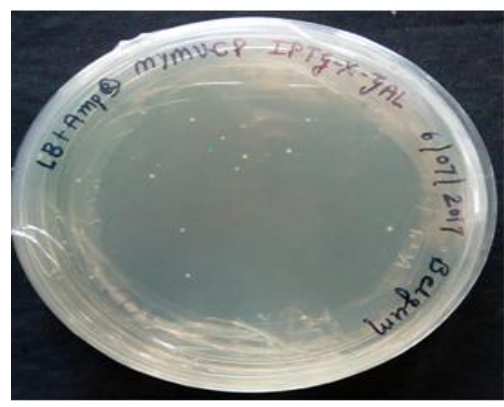

C

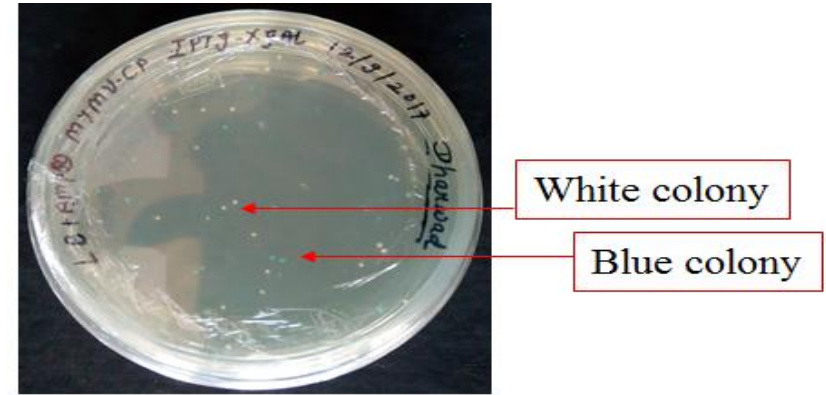

B

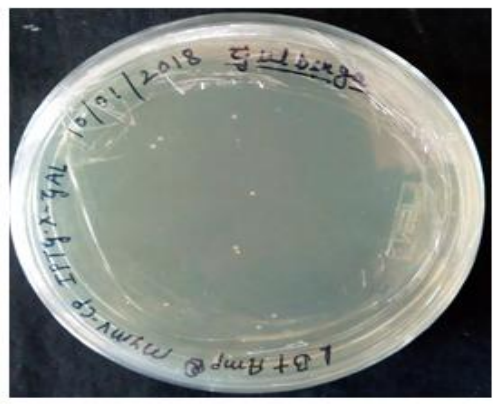

D

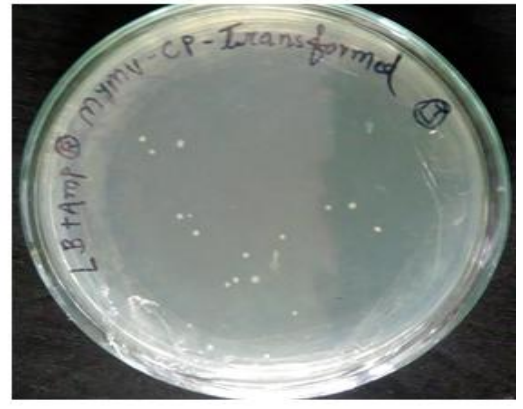

$\mathrm{E}$

Arrows are indicating blue and white colony.

A. Amravati isolate B. Dharwadisolate C. Belgum isolate D. Gulberga isolate E. Bengaluru isolate

Fig.3 Ethidium bromide stained agarose gel showing colony PCR confirmation of recombinant MYMV CP clones using gene-specific primers

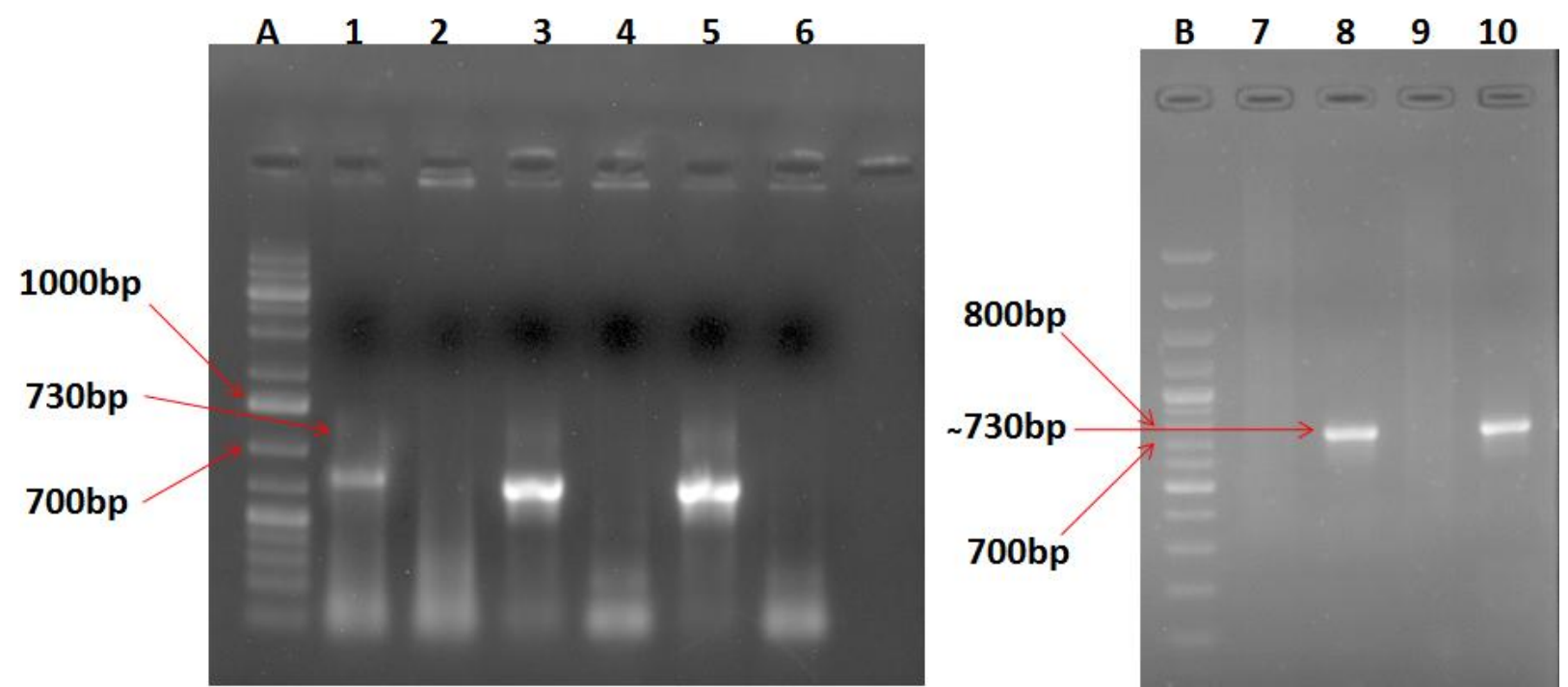

A-1 kb plus DNA ladder (75bp-2000bp), B-100bp DNA ladder (100-3000bp), 1-Dharwad isolate (White colony), 2Dharwad isolate (Blue colony), 3-Belgaum isolates (White colony), 4Belgaum isolates (Blue colony), 5-Amravati isolate (White colony), 6-Amravati isolate (Blue colony), 7- Gulbarga isolate (Blue colony), 8-Gulbarga isolate (White colony), 9-Bengaluru isolate (Blue colony) and 10-Bengaluru isolate (White colony) 
Fig.4 Ethidium bromide stained agarose gel showing $\mathrm{CP}$ gene amplification from recombinant plasmid using M13 primers

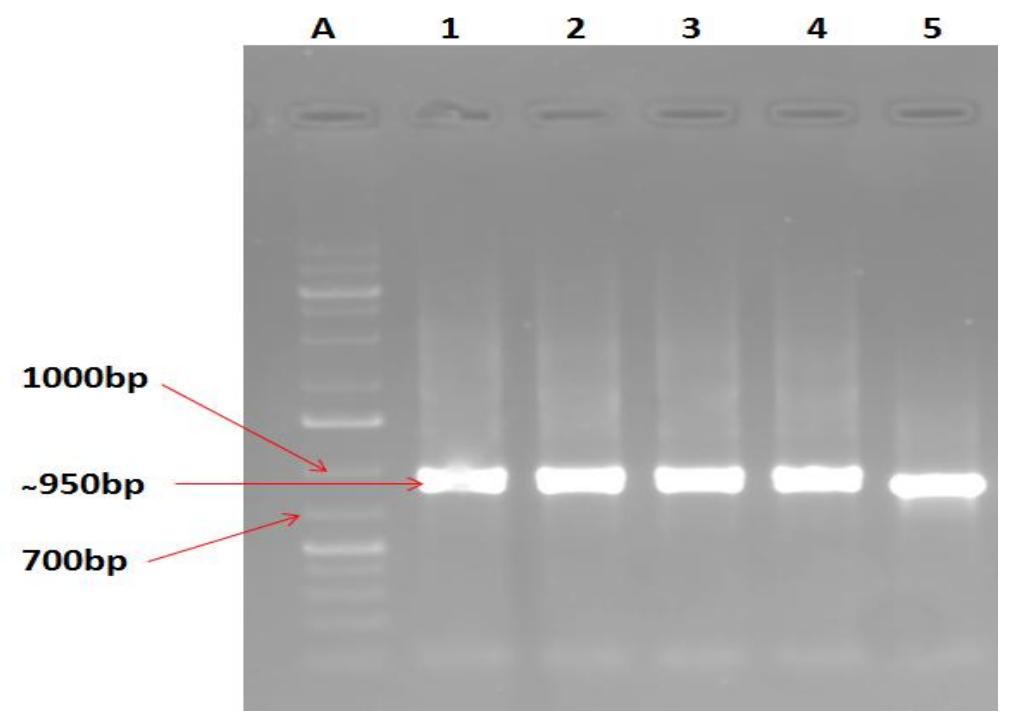

A-1 kb plus DNA ladder (75bp-2000bp), 1-Dharwad isolate, 2- Belgaum isolates, 3-Amravati isolate, 4- Gulbarga isolate and 5-Bengaluru isolate

Fig.5 Description of sequence producing significant alignment with MYMV CP gene by using BLAST tool (A: Dharwad isolate, B: Belgaum isolate, C: Amravati isolate, D: Gulbarga isolate, E: Bengaluru isolate)

\begin{tabular}{|c|c|c|c|c|c|c|c|c|}
\hline \multirow{13}{*}{ A } & & Description & $\max$ & Total & Query & E & tolent & Accession \\
\hline & (- & 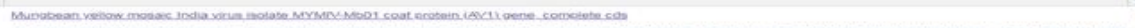 & 1260 & 1269 & $92 \%$ & 00 & $20 \%$ & $\$ 00207001.1$ \\
\hline & 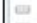 & 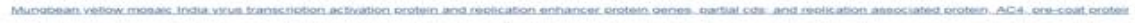 & 1250 & 1258 & $22 \%$ & 0.0 & s9\% & 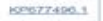 \\
\hline & 0 & 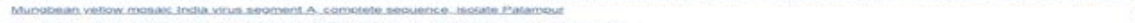 & 1250 & 1258 & 9256 & 0.0 & $99 \%$ & ENTOAZOO.1. \\
\hline & $\theta$ & 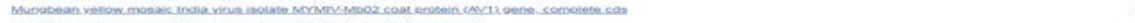 & 1258 & 1258 & $92 \%$ & 0.0 & $99 \%$ & 00302502. \\
\hline & $=$ & 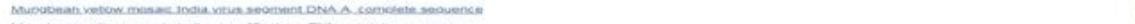 & 1250 & 1250 & $92 \%$ & 0.0 & 9926 & D050002152.1 \\
\hline & 0 & 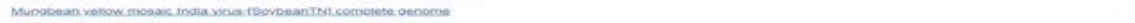 & 1250 & 1250 & $91 \%$ & 0.0 & $99 \%$ & astosse.t. \\
\hline & 0 & 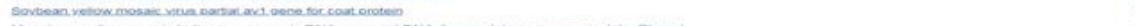 & 1200 & 1260 & 9286 & 0.0 & $90 \%$ & avasoon: \\
\hline & - & 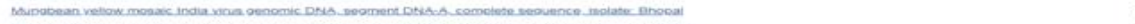 & 1263 & 1263 & 2206 & 0.0 & $90 \%$ & Leztiziaz: 1 \\
\hline & 0 & 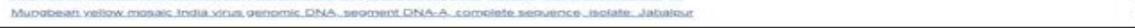 & 1253 & 1263 & $92 \%$ & 0.0 & $90 \% 6$ & 502737001 \\
\hline & $\square$ & 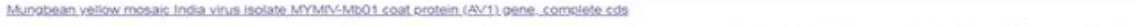 & 1269 & 1269 & $91 \%$ & 0.0 & $99 \%$ & 00397501.1 \\
\hline & e & 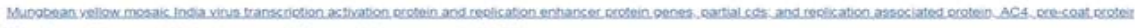 & 1258 & 1258 & $91 \%$ & 0.0 & $99 \%$ & KPQTZ2486.1. \\
\hline & $\square$ & 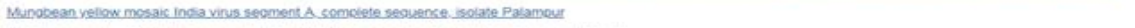 & 1258 & 1258 & $91 \%$ & 0.0 & $99 \%$ & EN79420011 \\
\hline \multirow{8}{*}{ B } & $\bullet$ & 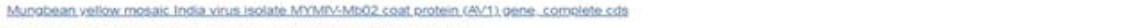 & 1258 & 1258 & $91 \%$ & 0.0 & $99 \%$ & $\$ 003975021$ \\
\hline & $\square$ & 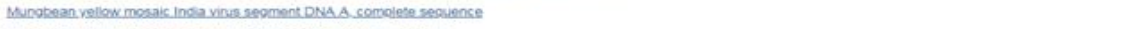 & 1258 & 1258 & $91 \%$ & 0.0 & $99 \%$ & DQ380153.1. \\
\hline & $\square$ & 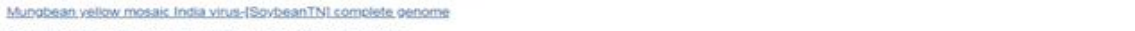 & 1258 & 1258 & $91 \%$ & 0.0 & $99 \%$ & A 4103491 \\
\hline & $\square$ & 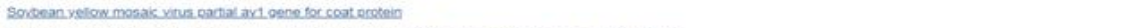 & 1258 & 1258 & $91 \%$ & 0.0 & $99 \%$ & Av315067.1 \\
\hline & 0 & 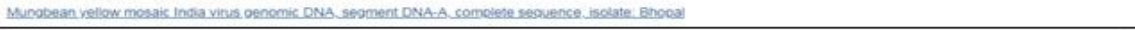 & 1253 & 1253 & $91 \%$ & 0.0 & $99 \%$ & $\$ C 2717921$ \\
\hline & 0 & 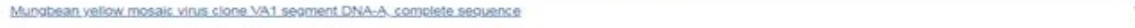 & 1230 & 1230 & $92 \%$ & 0.0 & $98 \%$ & KCen11722.1 \\
\hline & 0 & 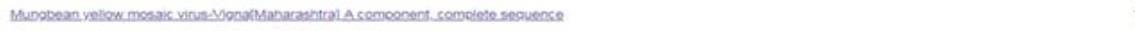 & 1230 & 1230 & $92 \%$ & 0.0 & $98 \%$ & AE 314530.1 \\
\hline & 0 & 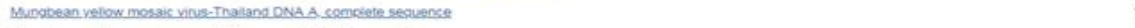 & 1225 & 1225 & $92 \%$ & 0.0 & $98 \%$ & $A 80173411$ \\
\hline \multirow[t]{8}{*}{$\mathrm{C}$} & 0 & 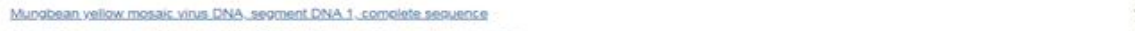 & 1225 & 1225 & $92 \%$ & 0.0 & $98 \%$ & D14703.1 \\
\hline & e & 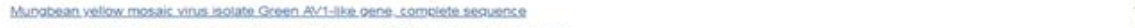 & 1219 & 1219 & $92 \%$ & 0.0 & $98 \%$ & kN6249001 \\
\hline & 0 & 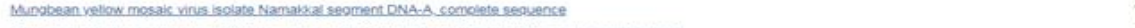 & 1219 & 1219 & $92 \%$ & 0.0 & $98 \%$ & DQ2065201.1. \\
\hline & $\theta$ & 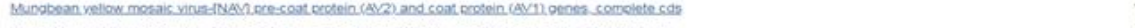 & 1219 & 1219 & $92 \%$ & 0.0 & $98 \%$ & D2392144.1 \\
\hline & 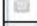 & 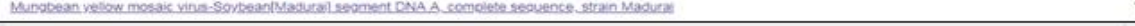 & 1219 & 1219 & $92 \%$ & 0.0 & $98 \%$ & Ava216421 \\
\hline & 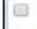 & 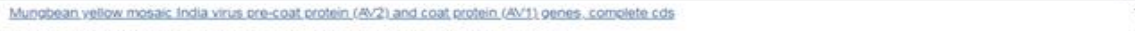 & 1395 & 1395 & $100 \%$ & 0.0 & $99 \%$ & 00392150.1 \\
\hline & $\square$ & 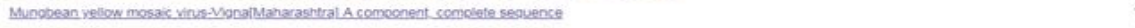 & 1395 & 1395 & $100 \%$ & 0.0 & $99 \%$ & AF 314530.1 \\
\hline & e & 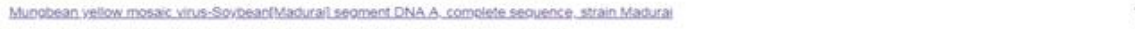 & 1391 & 1391 & $98 \%$ & 0.0 & $99 \%$ & $\$ 4216421$ \\
\hline \multirow{8}{*}{ D } & $\square$ & 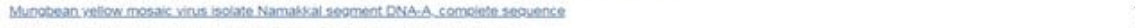 & 1384 & 1384 & $100 \%$ & 0.0 & $99 \%$ & Dosess201.1. \\
\hline & $\square$ & 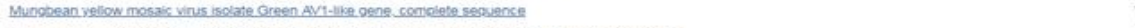 & 1382 & 1382 & $100 \%$ & 0.0 & 99\% & krazes202.1 \\
\hline & $\square$ & 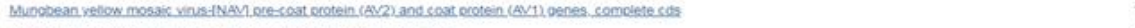 & 1378 & 1378 & $100 \%$ & 0.0 & $96 \%$ & DQ2029144.1 \\
\hline & $\square$ & 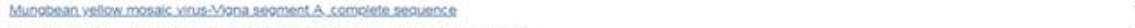 & 1378 & 1378 & $100 \%$ & 0.0 & $96 \%$ & Av132575.1 \\
\hline & 遇 & Mungbean vellicw mosalc virus clone CA2 segment DNA.A conclete seopense & 1373 & 1373 & $99 \%$ & 0.0 & $98 \%$ & Ko:111718.1 \\
\hline & $\square$ & 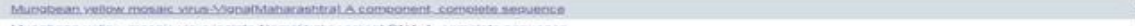 & 1225 & 1225 & sos & 00 & 9896 & Aearasso 1 \\
\hline & 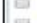 & 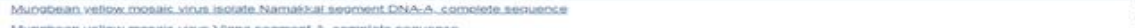 & 1219 & 1219 & $90 \%$ & 00 & $98 \%$ & 00005201.1 \\
\hline & $\square$ & 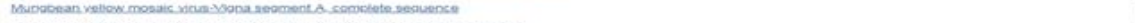 & 1219 & 1219 & $\infty 0 \%$ & 0.0 & $98 \%$ & on132025.1 \\
\hline \multirow{8}{*}{ E } & 0 & 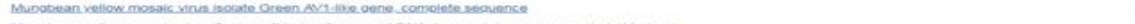 & 1214 & 1214 & $90 \%$ & 00 & $98 \%$ & broz29001 \\
\hline & 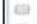 & 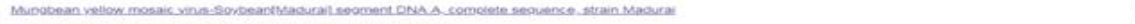 & 1214 & 1214 & $90 \%$ & 0.0 & 9896 & $\Delta 4216421$ \\
\hline & e & 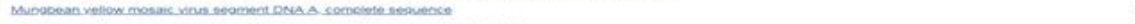 & 1208 & 1208 & $90 \%$ & 0.0 & $98 \%$ & Da4000934. \\
\hline & & 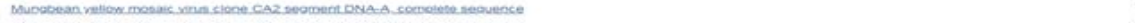 & 1203 & 1203 & $90 \%$ & 0.0 & $97 \%$ & kemenzies \\
\hline & $\square$ & 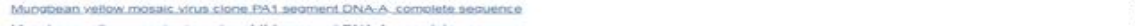 & 1203 & 1203 & $50 \%$ & 0.0 & $97 \%$ & kost17ziz: \\
\hline & $\square$ & 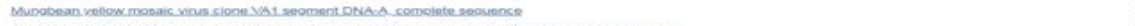 & 1197 & 1197 & $90 \%$ & 0.0 & $97 \%$ & Ko:11222: \\
\hline & 0 & 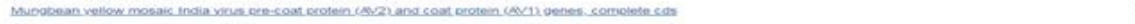 & 1197 & 1197 & $90 \%$ & 0.0 & $97 \%$ & D02392150.1. \\
\hline & 0 & 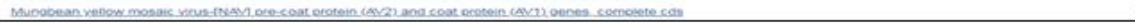 & 1192 & 1192 & $90 \%$ & 0.0 & $97 \%$ & \\
\hline
\end{tabular}


Fig.6 Multiple sequence alignment result for YMV CP gene sequence of 29 isolates including 5 isolates from the present study

CP1 Dharwad[Karnataka] CP2 Belgum [Karnataka] CP3 Amravati [Maharashtra] CP4 Gulberga [Karnataka] CP5 Bangalore [Karnataka] AF314530.1:301-1074 MYMV[Jalna :
DQ865201.1:302-1075 MYMV[Namak AJ132575.1:301-1074 MYMV[Madur. AJ421642.1:302-1075 MYMV-Soybe . KP455992.1:1931-2704 MYMV[Tiru . T DQ389144.1:301-1074 MYMV[Delhi . T KC911717.1:301-1074 MYMV[Panpo. DQ400848.1:302-1075 MYMV[Vamba DQ389144.1:301-1074 MYMV-[NAVS. DQ389150.1:300-1073 MYMIV [Aur . FN794200.1:316-1089 MYMIV [Pal DQ389153.1:316-1089 MYMIV [Del LC271792.1:385-1158 MYMIV [Bho LC271790.1:385-1158 MYMIV [Jab DQ389151.1:316-1089 MYMIV [Lud JN181003.1:116-889 MYMIV [Gunt GQ387507.1 MYMIV-Ub02 [Baraban KU950430.1:316-1089 MYMIV [Meg HF922628.1:315-1088 MYMIV [Wes KP779630.1:315-1088 MYMIV [Var KR052 025.1:316-1083 MYMIV [Luc
AY937195.1:316-1089 MYMIV [Ana AY937195.1:316-1089 MYMIV [Ana
KC911718.1:303-1076 MYMV [Coim

CP1 Dharwad[Karnataka] CP2 Belgum [Karnataka] CP3 Amravati [Maharashtra] CP4 Gulberga [Karnataka] CP5 Bangalore [Karnataka] AF314530.1:301-1074 MYMV[Jalna DQ865201.1:302-1075 MYMV[Namak . AJ132575.1:301-1074 MYMV[Madur . AJ421642.1:302-1075 MYMV-Soybe KP455992.1:1931-2704 MYMV[Tiru DQ389144.1:301-1074 MYMV[Delhi . KC911717.1:301-1074 MYMV[Panpo DQ400848.1:302-1075 MYMV[Vamba DQ389144.1:301-1074 MYMV-[NAVS. DQ389150.1:300-1073 MYMIV [Aur
FN794200.1:316-1089 MYMIV [Pal DQ389153.1:316-1089 MYMIV [Del AJ416349.1:316-1089 MYMIV [Soy LC271792.1:385-1158 MYMIV [Bho LC2 71790.1:385-1158 MYMIV [Jab DQ389151.1:316-1089 MYMIV [Lud JN181003.1:116-889 MYMIV [Gunt GQ387507.1 MYMIV-Ub02 [Baraban KU950430.1:316-1089 MYMIV [Meg HF922628.1:315-1088 MYMIV [Wes KP779630.1:315-1088 MYMIV [Var KR052025.1:316-1083 MYMIV [Luc

AY937195.1:316-1089 MYMIV [Ana

KC911718.1:303-1076 MYMV [Coim

CP1 Dharwad[Karnataka] CP2 Belgum [Karnataka] CP3 Amravati [Maharashtra] CP4 Gulberga [Karnataka] CP5 Bangalore [Karnataka] $\quad$ C C . C . . T AF314530.1:301-1074 MYMV[Jalna C C . C . . . DQ865201.1:302-1075 MYMV[Namak C . C . . AJ132575.1:301-1074 MYMV[MadurC C . C . . T AJ421642.1:302-1075 MYMV-Soybe C C . C . . T : G . KP455992.1:1931-2704 MYMV[Tiru C C . C . . DQ389144.1:301-1074 MYMV[Delhi C C . C . . ' KC911717.1:301-1074 MYMV[PanpoC C . C . . DQ400848.1:302-1075 MYMV[VambE C . C . . DQ389144.1:301-1074 MYMV-[NAVSC C . C . . DQ389150.1:300-1073 MYMIV [Aur C C . C . . T FN794200.1:316-1089 MYMIV [Pal DQ389153.1:316-1089 MYMIV [Del

C CT CTA C C C CGATA T CGAAT G CA CGGAGGAGATTGAA CT T CGATA C C C C C T CA

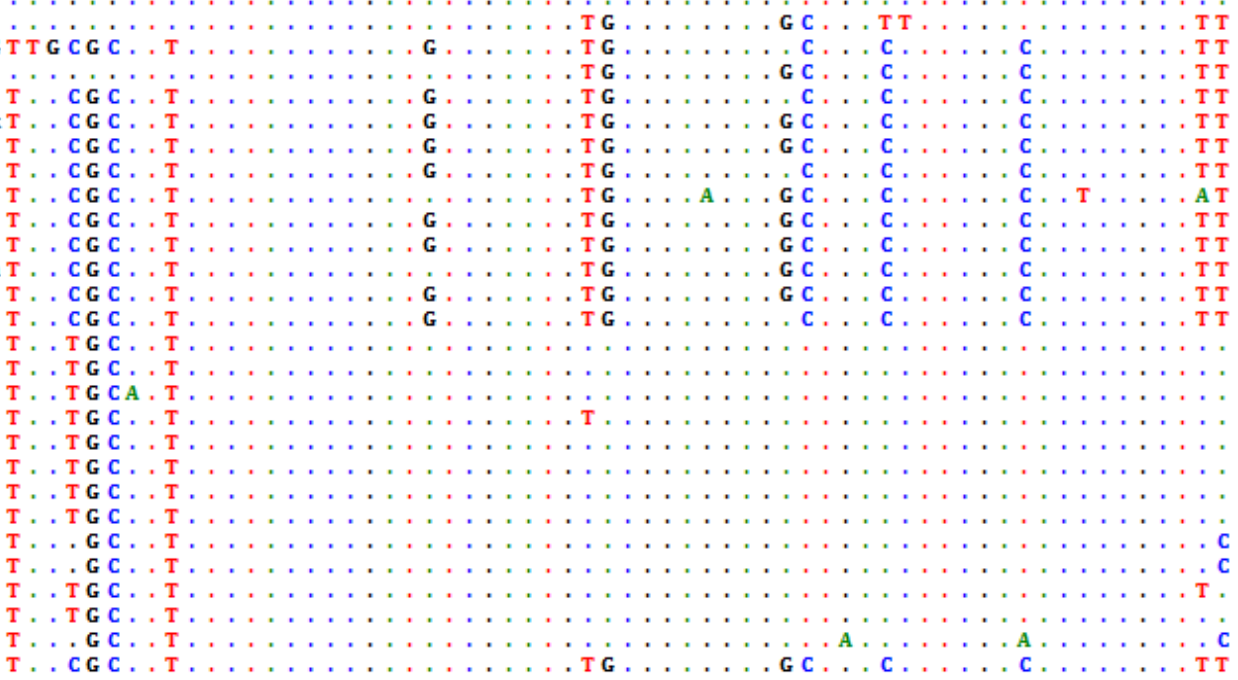

$901100 \quad 110 \quad 120 \quad 130 \quad 160$ GGAGGTGT C C CTA C CAACATGAAAAGAAGG CGT TGGACCAACCG C C CATGTGGAGGAACCT $\ldots A \ldots$. . . G . G G C . . . . A G . . . . . . . . . . . .

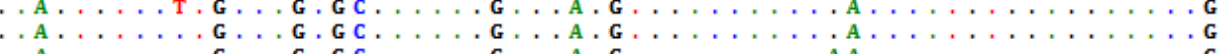

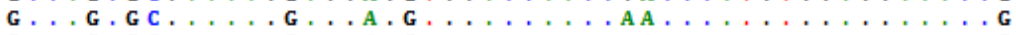

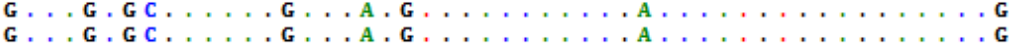

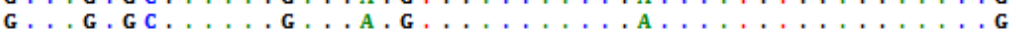
G G GC G G GC

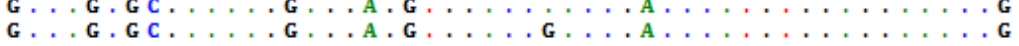

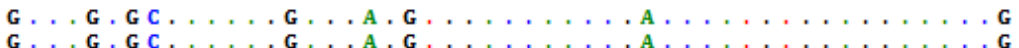

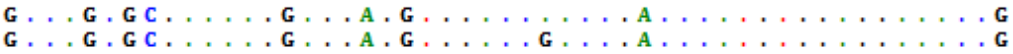

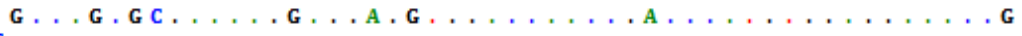

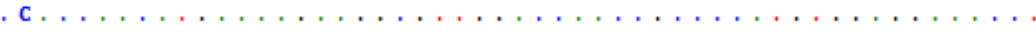
G . . A

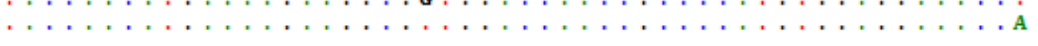
T. . . . . . . . . . . . . . . . . . . . . . . . G $\cdots$. G $\ldots$ A $A \ldots \ldots$ G $\ldots \ldots$ $17001800200 \quad 210 \quad 220$

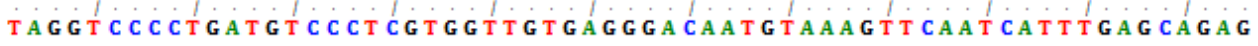
с $\mathbf{c}$ с $\ldots \ldots \ldots$. . . . . . . . . . . . . . . . . . . . . . . . . A $\ldots \ldots \ldots$. . . . . . . . A . . C T . . . . C . G . C . . . G C . A

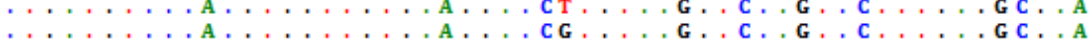
A..........

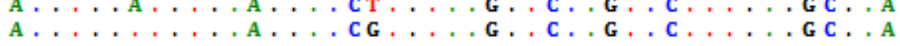

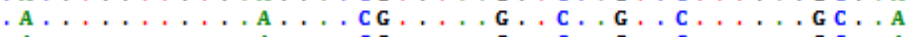

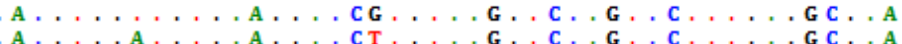

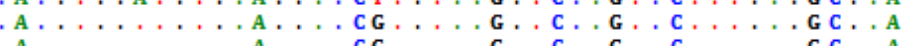

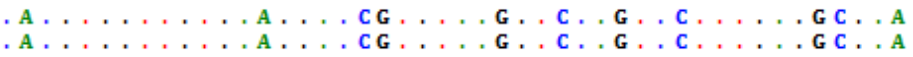

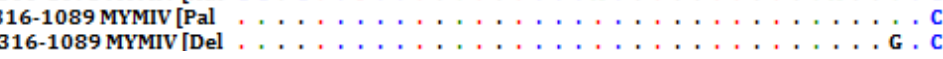

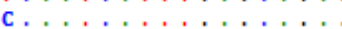


AJ416349.1:316-1089 MYMIV [Soy LC271792.1:385-1158 MYMIV [Bho LC271790.1:385-1158 MYMIV [Jab DQ389151.1:316-1089 MYMIV [Lud . JN181003.1:116-889 MYMIV [Gunt GQ387507.1 MYMIV-Ub02 [Baraban KU950430.1:316-1089 MYMIV [Meg HF922628.1:315-1088 MYMIV [Wes KP779630.1:315-1088 MYMIV [Var KR052025.1:316-1083 MYMIV [Luc AY937195.1:316-1089 MYMIV [Ana KC911718.1:303-1076 MYMV [Coim

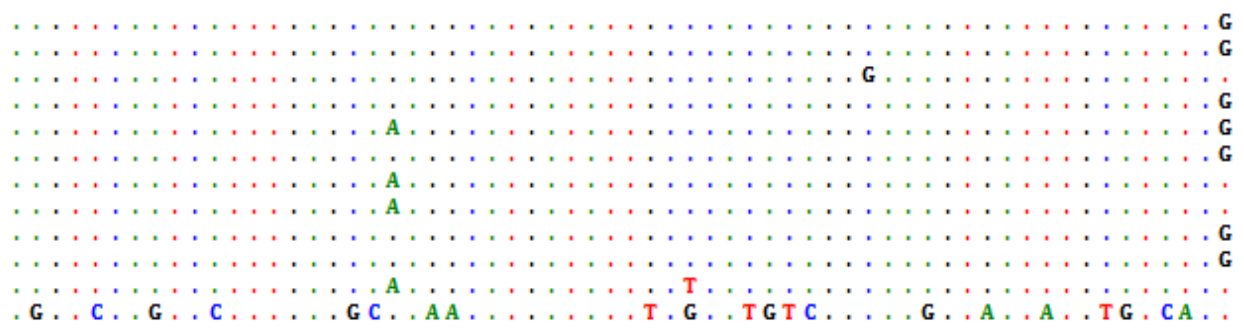

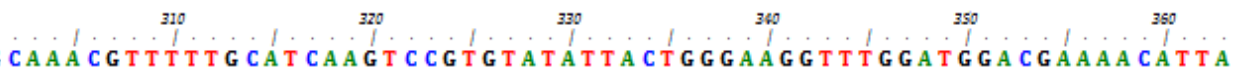

CP1 Dharwad[Karnataka] CP2 Belgum [Karnataka] CP3 Amravati [Maharashtra] CP4 Gulberga [Karnataka]

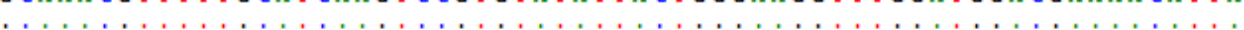
AF314530.1:301-1074 MYMV[Jalna AF314530.1:301-1074 MYMVUjalna
DQ865201.1:302-1075 MYMV[Namak
AJ132575.1:301-1074 MYMV[Madur. AJ421642.1:302-1075 MYMV-Soybe . KP455992.1:1931-2704 MYMV[Tiru . G DQ389144.1:301-1074 MYMV[Delhi . KC911717.1:301-1074 MYMV[Panpo. G DQ400848.1:302-1075 MYMV[Vamba DQ389144.1:301-1074 MYMV-[NAVS. G DQ389150.1:300-1073 MYMIV [Aur . FN794200.1:316-1089 MYMIV [Pal DQ389153.1:316-1089 MYMIV [Del AJ416349.1:316-1089 MYMIV [Soy LC271792.1:385-1158 MYMIV [Bho LC271790.1:385-1158 MYMIV [Jab DQ389151.1:316-1089 MYMIV [Lud . JN181003.1:116-889 MYMIV [Gunt GQ387507.1 MYMIV-Ub02 [Baraban KU950430.1:316-1089 MYMIV [Meg . HF922628.1:315-1088 MYMIV [Wes KP779630.1:315-1088 MYMIV [Var KR052025.1:316-1083 MYMIV [Luc AY937195.1:316-1089 MYMIV [Ana KC911718.1:303-1076 MYMV [Coim

\begin{tabular}{|c|}
\hline 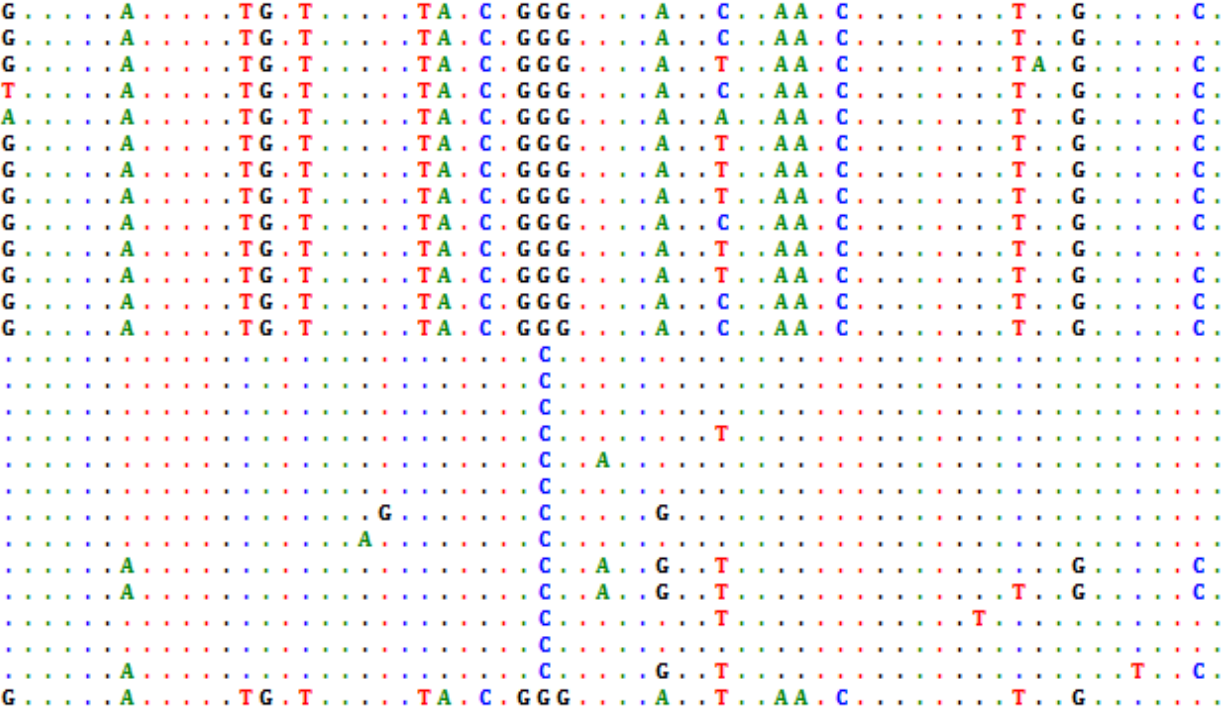 \\
\hline
\end{tabular}

CP1 Dharwad[Karnataka] CP2 Belgum [Karnataka] CP3 Amravati [Maharashtra] CP4 Gulberga [Karnataka] CP5 Bangalore [Karnataka] AF314530.1:301-1074 MYMV[Jalna DQ865201.1:302-1075 MYMV[Nama AJ132575.1:301-1074 MYMV[Madur. G T AJ421642.1:302-1075 MYMV-Soybe . G T G KP455992.1:1931-2704 MYMV[Tiru , G T G DQ389144.1:301-1074 MYMV[Delhi . G T KC911717.1:301-1074 MYMV[Panpo. G T G DQ400848.1:302-1075 MYMV[Vamba G T G DQ389144.1:301-1074 MYMV-[NAVS. G T G DQ389150.1:300-1073 MYMIV [Aur , G T G FN794200.1:316-1089 MYMIV [Pal DQ389153.1:316-1089 MYMIV [Del AJ416349.1:316-1089 MYMIV [Soy LC271792.1:385-1158 MYMIV [Bho LC271790.1:385-1158 MYMIV [Jab DQ389151.1:316-1089 MYMIV [Lud JN181003.1:116-889 MYMIV [Gunt GQ387507.1 MYMIV-Ub02 [Baraban KU950430.1:316-1089 MYMIV [Meg HF922628.1:315-1088 MYMIV [Wes KP779630.1:315-1088 MYMIV [Var KR052025.1:316-1083 MYMIV [Luc AY937195.1:316-1089 MYMIV [Ana KC911718.1:303-1076 MYMV [Coim

CP1 Dharwad[Karnataka] CP2 Belgum [Karnataka] CP3 Amravati [Maharashtra] CP4 Gulberga [Karnataka]

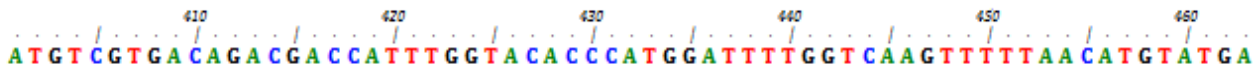

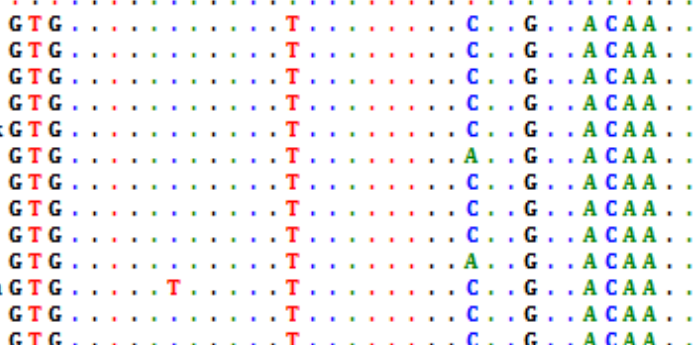

\section{G}

,

,




\begin{tabular}{|c|c|}
\hline & $\begin{array}{l} \\
\mathrm{G}_{\mathrm{G}} \mathrm{G} \\
\mathrm{G}\end{array} \mathrm{G}$ \\
\hline
\end{tabular}

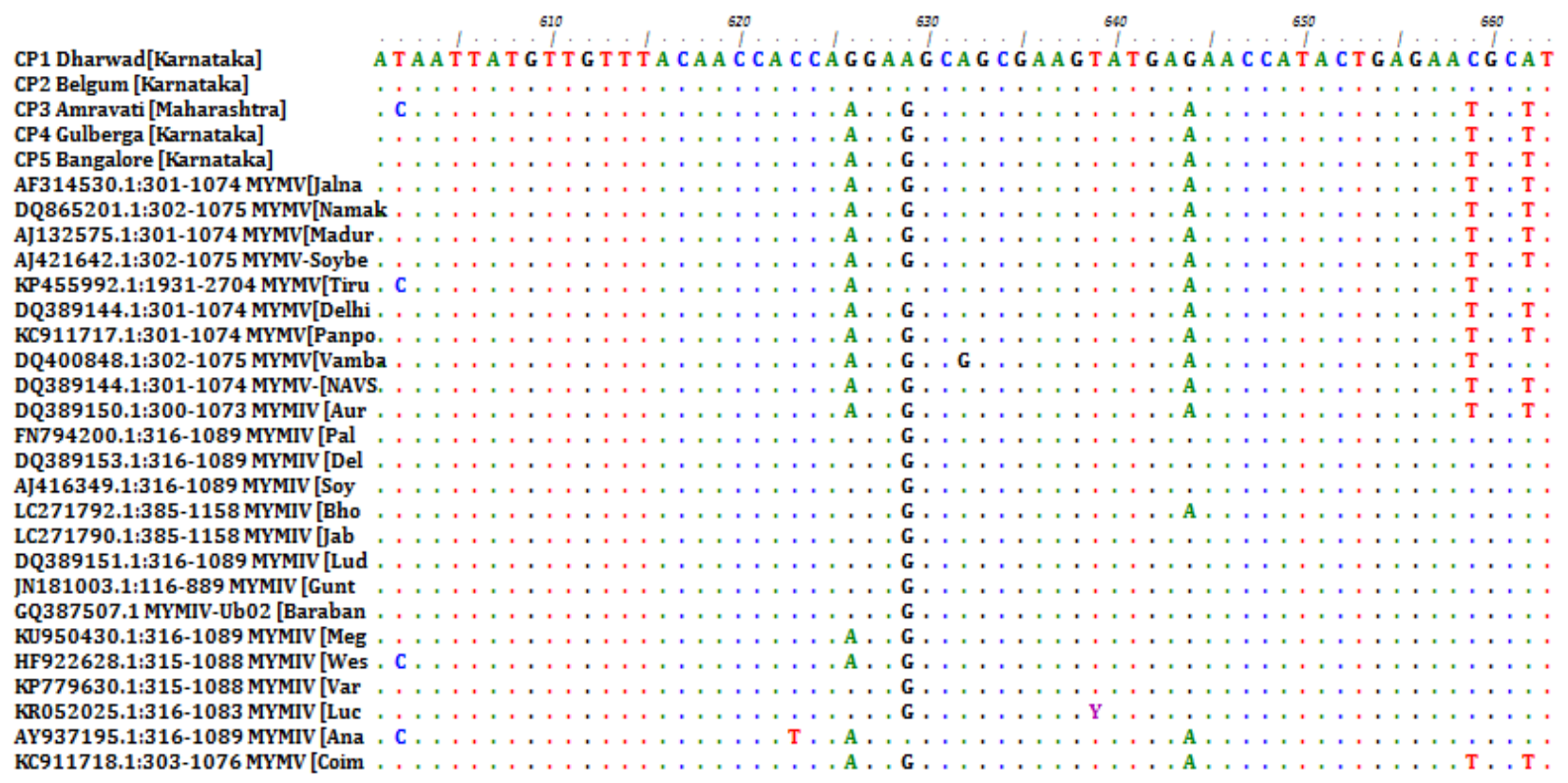

CP1 Dharwad[Karnataka] CP2 Belgum [Karnataka] CP3 Amravati [Maharashtra] CP4 Gulberga [Karnataka] CP5 Bangalore [Karnataka]

AF314530.1:301-1074 MYMV[Jalna DQ865201.1:302-1075 MYMV[Nama AJ132575.1:301-1074 MYMV[Madur. . . . . . . . . . . . . A T T G AAAAT . AJ421642.1:302-1075 MYMV-Soybe . . . . . . . C . . . . . A A T T A AAAT . KP455992.1:1931-2704 MYMV[Tiru . . . . . . . . . . A T T G A A A A T . DQ389144.1:301-1074 MYMV[Delhi . . . . . . . . . . . A C T G A A A A T . KC911717.1:301-1074 MYMV[Panpo. . . . . . . . . . . A T T G A A A A T . DQ400848.1:302-1075 MYMV[Vamba . . . . . . . . . . A T T G A A A A T . DQ389144.1:301-1074 MYMV-[NAVS. . . . . . . . . . A C T G A A A A T . DQ389150.1:300-1073 MYMIV [Aur . . . . . C . . . . A T T G A A A A T FN794200.1:316-1089 MYMIV [Pal C . . . . . . . . . A C T . A A A A T . DQ389153.1:316-1089 MYMIV [Del . . . . . . . . . A C T . A A A A T . AJ416349.1:316-1089 MYMIV [Soy . . . . . . . . . . A C T . A A A A T . LC271792.1:385-1158 MYMIV [Bho ............ A C T , A A A A T LC271790.1:385-1158 MYMIV [Jab . . . . . . . . A C T . A A A A T DQ389151.1:316-1089 MYMIV [Lud . . . . . . . . . A C T . A A A A T . JN181003.1:116-889 MYMIV [Gunt . . . . . . . . . A C T . A A A A T . GQ387507.1 MYMIV-Ub02 [Baraban . . . . . . . . . . . A C T . A A A A T . 
Fig.7 Matrix showing pairwise percent identities of $\mathrm{CP}$ nucleotide sequences among YMV isolates

KU950430.1_3161089_MYMN_[Meghalaya] HF922628.1_3151088_MYMN_[West_Bengal] AY937195.1_3161089_MYMN_[Anand,_Gujrat

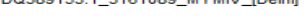
LC271790.1_3851158_MMNMN_Jabalpur_MP] KR:

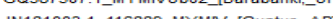
FN794000.100 AJ416349.1_3161089_MYMN_[Soybean_TN] AJ416349.1_3161089_HAYAN_L_Soybean_TME_ LC271792.1_3851158_Mr.MN_LBhopa__MP KP779630.1_3151088_MrMN_Naranasi] Da389151.1_3161089_MYMN__Ludhiyana,_Haryana CP1_Dharwad[Karnataka]

CP2_Belgum_[Karnataka]

CP3_Amravati_Maharashtra]

CP5_Bangalore_[Karnataka]

CP4_Gulberga_[Karnataka]

DQ389150.1_3001073_MYMN_[Aurangabad_MH]

DQ389144.1_3011074_MYMV[Delhi]

DQ389144.1_3011074_MYMMVINAVSARI_

AF314530.1_3011074_MYMVIJalna,_Maharashtra]

AJ421642.1_3021075_MYMVSoybean[Madurai]_

DQ865201.1_3021075_MYMVINamakka]]

AJ132575.1_3011074_MYMVIMadurain

KC911717.1_3011074_MYMVYPanpozhi_

DQ400848.1_3021075_MYMVTVamban]

KC911718.1_3031076_MYMV_[Coimbatore,_TN]

KP455992.1_19312704_MYMV[Tirupati]
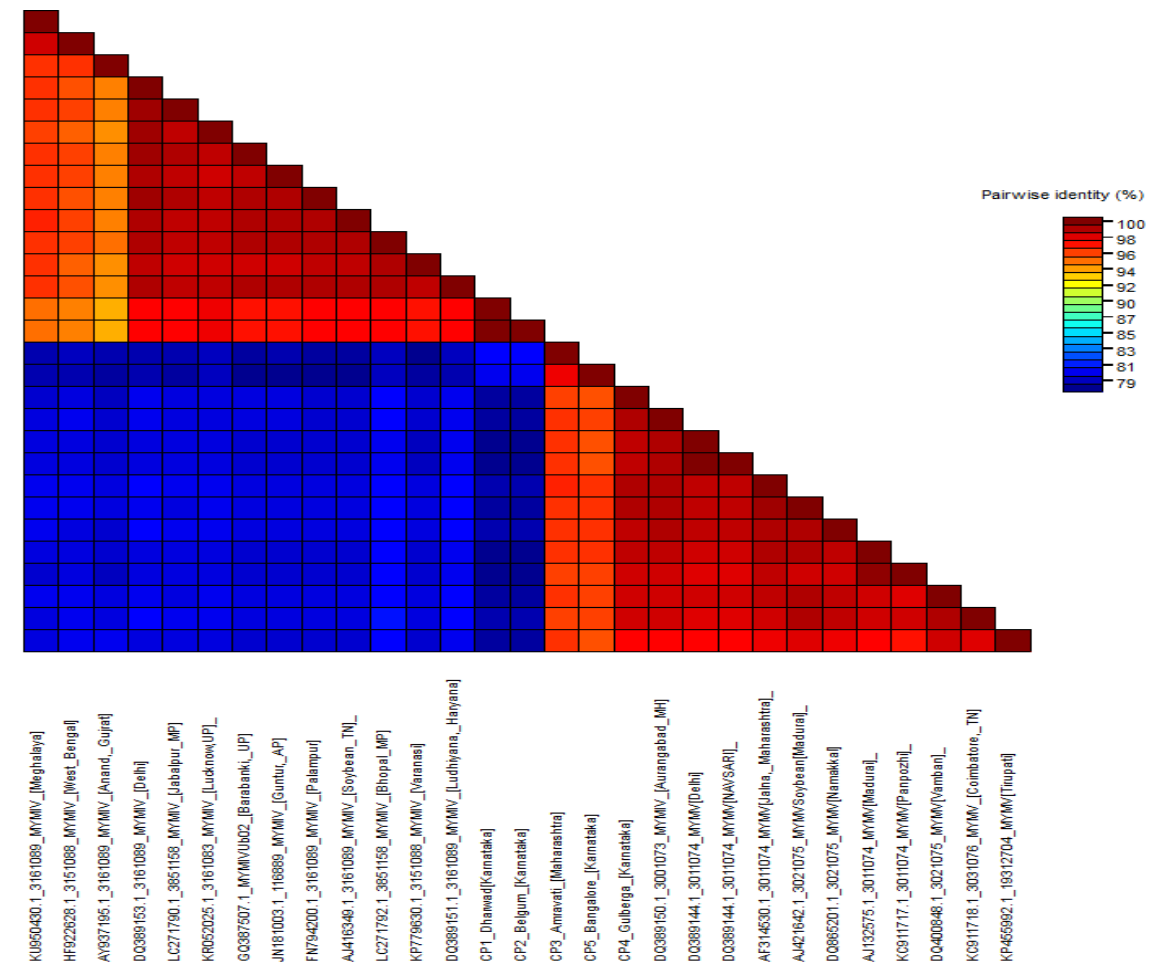

Fig.8 Plot depicting pairwise percent identities of CP nucleotide sequences among YMV isolates

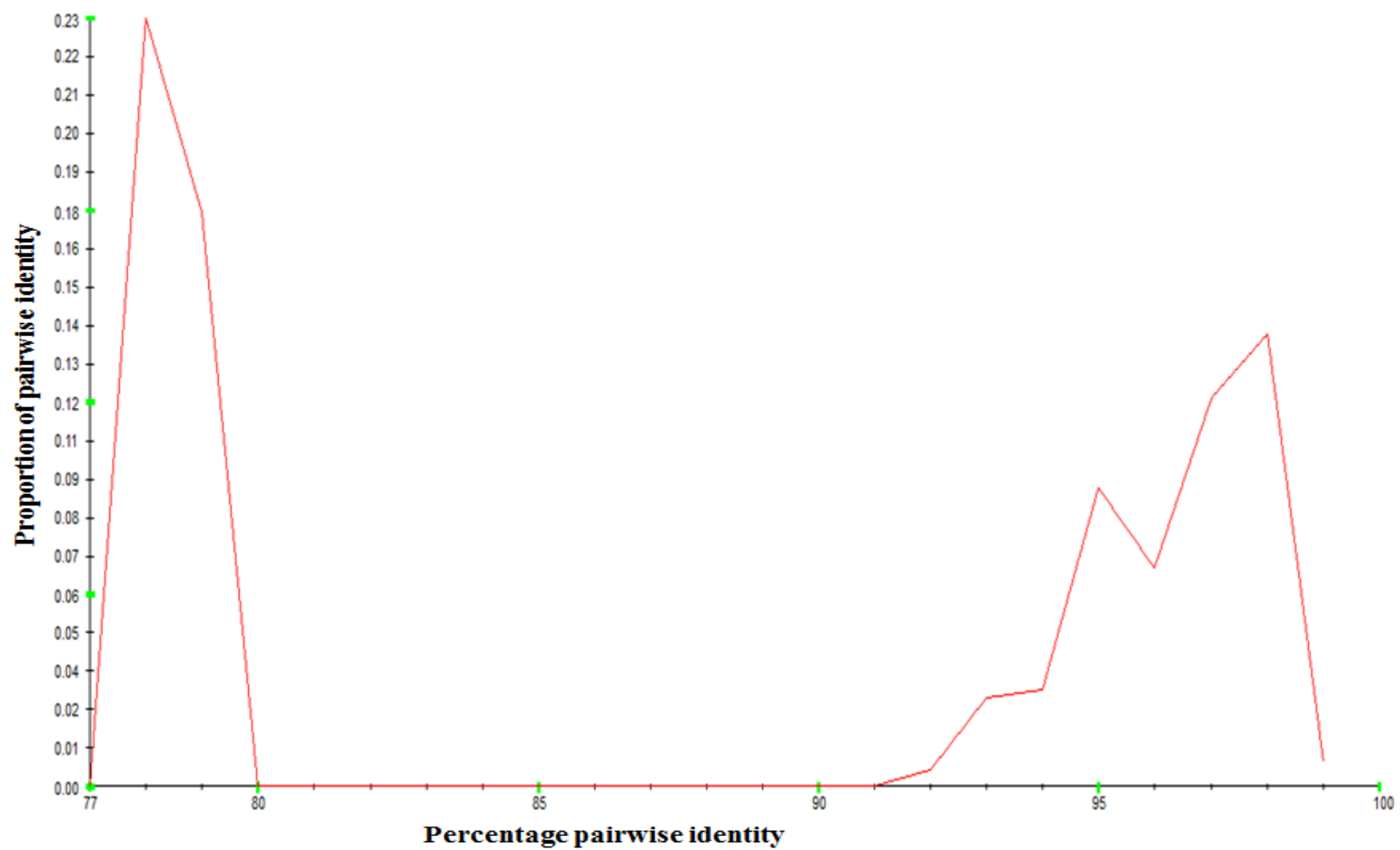


Fig.9 Phylogenetic tree based on nucleotide sequence of YMV CP genes of 29 isolates

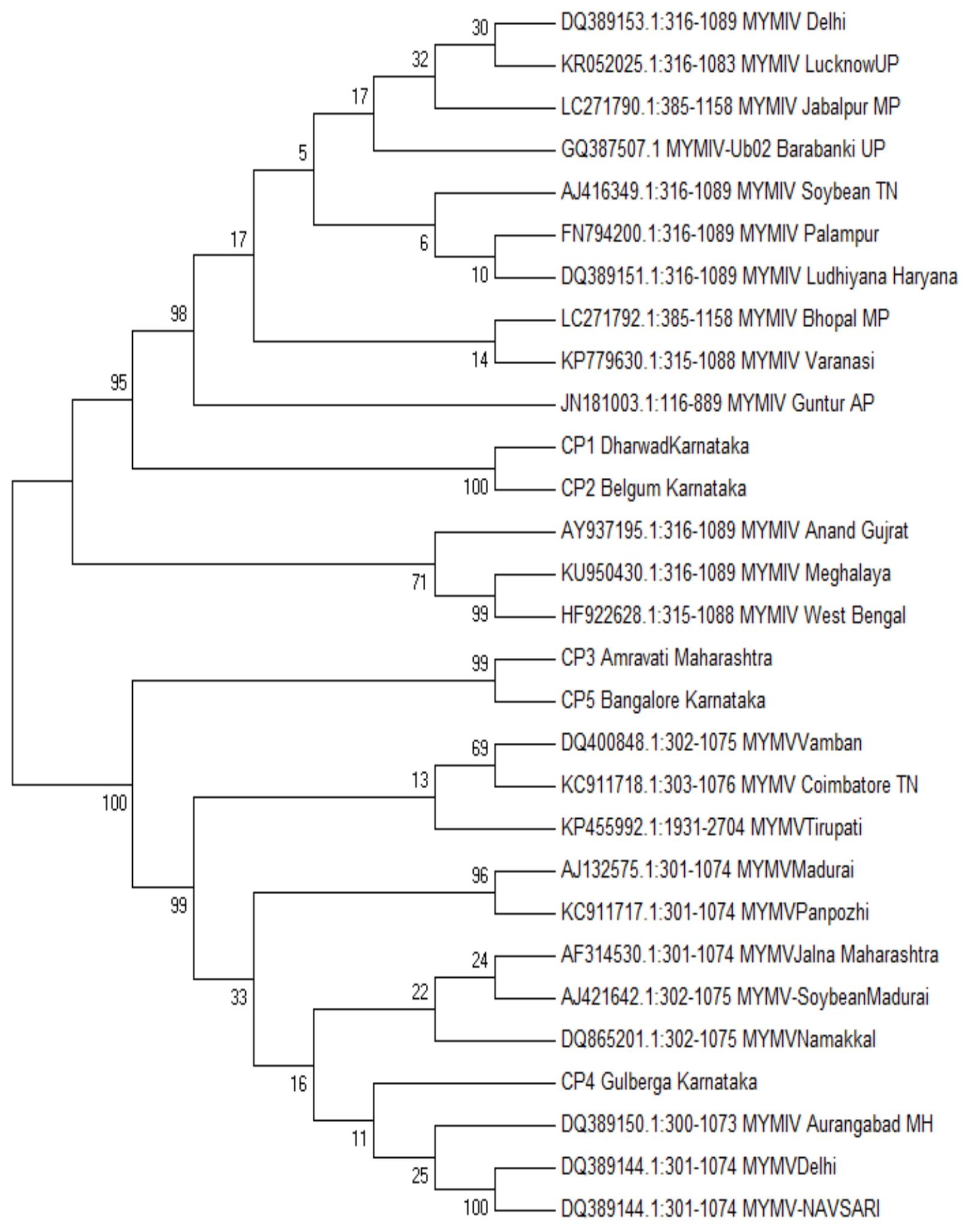




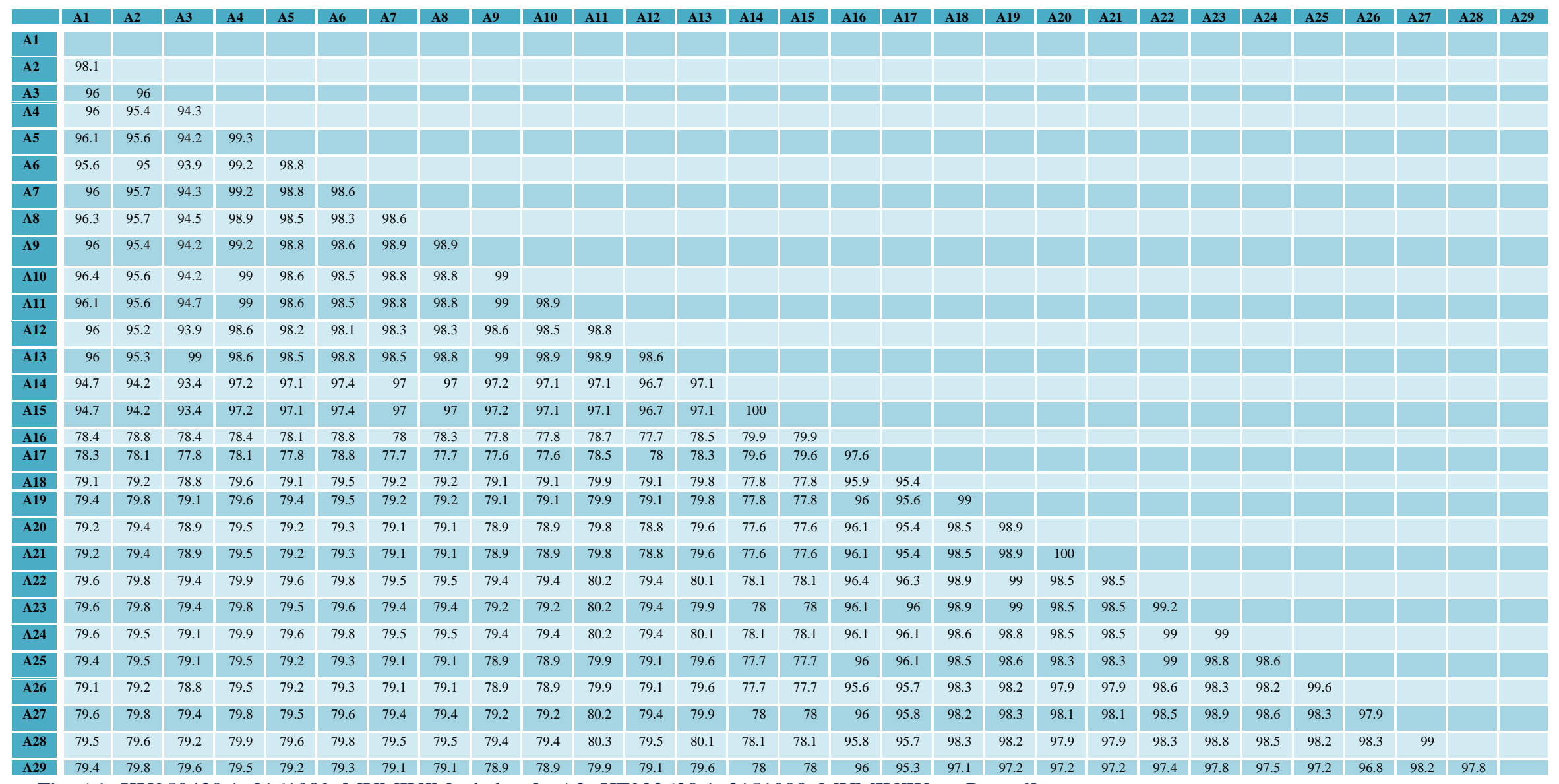

Fig. A1-KU950430.1_3161089_MYMIV[Meghalaya] ; A2-HF922628.1_3151088_MYMIV[West_Bengal];

A3- AY937195.1_3161089_MYMIV[Anand,_Gujrat]; A4- DQ389153.1_3161089_MYMIV[Delhi]; A5-LC271790.1_3851158_MYMIV[Jabalpur_MP]; A6KR052025.1_3161083_MYMIV[Lucknow,UP]; A7- GQ387507.1_MYMIVUb02[Barabanki,_UP]; A8- JN181003.1_116889_MYMIV[Guntur,_AP]; A9-

FN794200.1_3161089_MYMIV[Palampur]; A10- AJ416349.1_3161089_MYMIV[Soybean_TN]; A11-LC271792.1_3851158_MYMIV[Bhopal_MP]; A12KP779630.1_3151088_MYMIV[Varanasi]; A13- DQ389151.1_3161089_MYMIV[Ludhiyana,_Haryana]; A14- CP1_Dharwad[Karnataka]; A15-

CP2_Belgum[Karnataka]; A16-CP3_Amravati[Maharashtra]; A17- CP5_Bangalore[Karnataka]; A18- CP4_Gulberga[Karnataka];

A19-DQ389150.1_3001073_MYMIV[Aurangabad_MH]; A20-DQ389144.1_3011074_MYMV[Delhi]; A21- DQ389144.1_3011074_MYMV[NAVSARI]; A22- AF314530.1_3011074_MYMV[Jalna,_Maharashtra]; A23- AJ421642.1_3021075_MYMVSoybean[Madurai]; A24-

DQ865201.1_3021075_MYMV[Namakkal]; A25- AJ132575.1_3011074_MYMV[Madurai]; A26- KC911717.1_3011074_MYMV[Panpozhi]; A27-

DQ400848.1_3021075_MYMV[Vamban]; A28-KC911718.1_3031076_MYMV[Coimbatore, TN]; A29- KP455992.1_19312704_MYMV[Tirupati] 
Per cent identity study for nucleotide sequence among the isolates

The pairwise per cent identities calculated by SDTv1.1 program depicted in Fig.7 and Fig. 8 gives broad estimates of identities among the sequences. The highest pairwise identity (9899\%) were shown by approximately $13.9 \%$ of the total 29 sequences taken for study followed by approximately $7 \%$ of the sequences which showed $95-98 \%$ pairwise identity. The lowest pairwise identities (77$78 \%$ ) were shown by approximately $23 \%$ of the total sequences. The pairwise identity 80 $91 \%$ were shown by the least proportion of the sequences $(<1 \%)$.

An accurate estimation of pairwise per cent identities among the studied sequences calculated by neighbor joining method of SDTv1.2 program is given in Table 1 . The pairwise sequence identities at nucleotide level within five isolates used in the present study were 79.6 per cent (CP1 Dharwad CP5 Bangalore, CP2 Belgum -CP5 Bangalore), 97.6 per cent (CP3 Amravati CP5 Bangalore), 77.8 per cent (CP1 Dharwad -CP4 Gulberga, CP2 Belgum - CP4 Gulberga), 95.9 per cent (CP3 Amravati CP4 Gulberga) 95.4 per cent (CP4 Gulberga CP5 Bangalore) (Table 1).

\section{Phylogenetic analysis of MYMV CP gene sequences}

Phylogenetic analyses were conducted using MEGA7 program with bootstrap value of 1500 replications to estimate the confidence of branching patterns for UPGMA. Branches corresponding to partitions reproduced in less than $50 \%$ bootstrap replicates are collapsed. The percentage of replicate trees in which the associated taxa clustered together in the bootstrap test (1500 replicates) is shown next to the branches (Felsenstein, 1985). The evolutionary distances were computed using the p-distance method (Nie, 2000) and are in the units of the number of base differences per site. The bootstrap consensus tree inferred from 1500 replicates (Fig. 9) clearly divided 29 nucleotide sequences into two major clusters. All positions containing gaps and missing data were eliminated. First cluster from the top mostly comprised of MYMIV strain which predominates the area like Northern India (Delhi, Lucknow, Barabanki, Ludhiyana, Palampur, varanasi), Central India (Jabalpur, Bhopal and Anand- Gujrat), North East India (Meghalaya) and West Bengal including one South Indian strain (Guntur, $\mathrm{AP})$. The second large cluster comprised of mostly MYMV strain except one MYMIV strain from Aurangabad, Maharashtra. It includes MYMV strain which predominantly occurs in Southern India (Tirupati, Vamban, Coimbatore, Madurai, Panpozhi and Namakkal), one strain from Delhi, Navsari (Gujrat), Jalna (Maharashtra). The isolates from Dharwad and Belgum from the present study were placed in first cluster supported their identification as MYMIV strain. Remaining three isolates from Amravati, Gulberga and Bengaluru were placed in second cluster supported their identity as MYMV strain. (Fig. 9).

Homology study of the amplified CP gene sequence from the isolates of Dharwad and Belgaum with BLAST algorithm provisionally identified them as MYMIV isolates. The pairwise identity percentage revealed by SDTv1.2 program supported their identity as MYMIV isolates (Fig. 7 and Table 1). The dendrogram (Fig. 9) generated for the CP gene sequences of 29 isolates broadly classified the isolates in two groups as MYMIV and MYMV, showing that the MYMIV isolates were predominant in Central, North and North-East India. The nucleotide diversity and DNA polymorphism studied (Ramesh et al., 2017; Usharani et al., 2004), revealed MYMIV strain predominantly 
infecting legumes in Central, North and North-East India.

Molecular identification of yellow mosaic disease and characterization of YMV coat protein (CP) gene was carried out in Bangladesh (Islam et al., 2012). Sequence analysis of the PCR amplified product showed $97 \%$ sequence similarity with the coat protein gene of MYMIV Bangladesh strain and was designated as MYMIV- BD. This study conducted in Bangladesh revealed a result similar to the study carried out in present research.

Naimuddin et al., (2011) characterized the virus by designing several sets of primer pairs to amplify the targeted DNA fragments of the causal virus of YMD at Kanpur. Comparative analysis of the coat protein (AV1) gene of the virus under study (FJ821189) showed a 97 and 99\% similarity with MYMIV-Mungbean strain at the nucleotide and the amino acid levels respectively. Therefore, the begomovirus infecting $V$. mungo var. silvestris at Kanpur is to be considered as a strain of MYMIV.

Virus isolates causing the disease in soybean and other grain legumes are diverse despite no apparent differences in the visible symptoms. In northern and western parts of India MYMIV and MYMV cause the disease in soybean respectively (Girish et al., 2005; Usharani et al., 2004). In Central India, where cultivation of soybean is a major Kharif crop, incidence of MYMIV was observed (Ramesh et al., 2013).

The amplified $\mathrm{CP}$ gene sequence from the isolates of Amravati, Gulbarga and Bengaluru analyzed by BLAST identifies them as MYMV. The pairwise identity percentage revealed by SDTv1.2 program supported their identity as MYMV isolates (Fig. 7 \& Table 1). The dendrogram (Fig. 9) generated for the
CP gene sequences of 29 isolates grouped these isolates (Amravati, Gulbarga and Bengaluru) into the cluster carrying mostly MYMV isolates, showing that the MYMV isolates were predominant in Southern India.

Prema and Rangaswami (2018) carried out phylogenetic analysis of the coat protein gene sequence of yellow mosaic virus infecting mungbean at Hebbal (Bengaluru) and confirmed the identity of virus as MYMV. Analysis of nucleotide sequence of coat protein gene of yellow mosaic virus associated with mungbean showed maximum identity with $99 \%$ MYMV-Maharashtra: SB (AF314530.1), followed by 98.9\% with MYMV-Namakka 1: MoB (DQ865201.1) as well as MYMV-Tamil Nadu: MB (AJ132575.1) and 98.8\% with MYMVMadurai: SB isolates (AJ421642.1).

Geographical confinement of species of yellow mosaic viruses infecting soybean is validated as diseased soybean samples collected from Northern and Central India showed infection due to MYMIV and samples obtained from southern and western India were infected with MYMV (Maheshwari et al., 2014). It has also been suggested that MYMV causes severe YMD in green gram and black gram in Southern parts of India (Karthikeyan et al., 2004). The nucleotide sequence data of genomic components of YMV classified begomovirus into two distinct strain as MYMIV (Mandal et al., 1997) and MYMV (Morinaga et al., 1990) were suggested to be associated with the etiology of YMD in legumes in south Asia including India.

Narrow host range within legumes and indistinguishable symptoms of YMV made specific identification of the viruses difficult (Pant et al., 2001) as shows related but having distinct and overlapping legume host range. Because of infecting wide range of legumes, 
the virus strain MYMV and MYMIV are most important in India, amidst them MYMIV is more prevalent in northern, central and eastern regions of India (Usharani et al., 2004) whereas, MYMV is predominant in the southern and western regions (Girish and Usha, 2005; Karthikeyan et al., 2004).

The decisive management of YMD is largely determined by resistance breeding and also development of transgenic resistance to YMV. Thus it is imperative to understand the relationship between YMV affecting different legumes, as well as, to consider the diversity among the various isolates of the virus in order to employ right management strategy for YMV infecting mungbean.

\section{References}

Banerjee, A., Y. Umbrey, R. M. Yadav and Roy, S. 2018. Molecular evidence of an isolate of mungbean yellow mosaic India virus with a recombinant DNA B component occurring on mungbean from mid-hills of Meghalaya. India. Virus Dis. 29(1): 68-74.

Birmbion, H.C. and Doly, J. 1979. A rapid alkaline extraction procedure for screening recombinant plasmid DNA. Nucl. Acids Res., 7(6): 1513-23.

Brown, J.K., A.M. Idris, Torres-Jerez., G.K., Banks and Wyatt, S.D. 2001. The core region of the coat protein gene is highly useful for establishing the provisional identification and classification of begomoviruses. Arch. Virol. 146(8): 1581-1598.

Felsenstein, J. 1985. Confidence limits on phylogenies: An approach using the bootstrap. Evol. 39, 783-791.

Girish, K.R. and Usha, R. 2005. Molecular characterization of two soybean infecting begomoviruses from India and evidence for recombination among legume-infecting begomoviruses from
South-East Asia. Vir. Res. 108, 16776.

Ha, C., S. Coombs, P. Revill, R. Harding, M. $\mathrm{Vu}$ and James D. 2008. Molecular characterization of begomoviruses and DNA satellites from Vietnam: Additional evidence that the New World geminiviruses were present in the Old World prior to continental separation. J. Gen. Virol. 89, 312-326.

Idris, A. M. and Brown, J. K. 1998. Sinaloa tomato leaf curl geminivirus: Biological and molecular evidence for a new subgroup III virus. Phytopathol. 88, 648-657.

Islam, M. N., K. S., Sony, and Borna, S. R. 2012. Molecular characterization of mungbean yellow mosaic disease and coat protein gene in mungbean varieties of Bangladesh. Pl. Tissue Cult. Biotech. 22(1): 73- 81 .

Karthikeyan, A.S., R. Vanitharani, V. Balaji, S. Anuradha, P. Thillaichidambaram, P.V. Shivaprasad, C., Parameswari, V. Balamani, M. Saminathan, and Veluthambi, K. 2004. Analysis of an isolate of mungbean yellow mosaic virus (MYMV) with a highly variable DNA B component. Arch Virol. 149, 1643-1652.

Kumar, S., B. Tanti, S. K. Mukherjee and Sahoo, L. 2017. Molecular characterization and infectivity of mungbean yellow mosaic India virus associated with yellow mosaic disease of cowpea and mungbean. Biocatal. Agric. Biotechnol. 11, 183-191.

Maheshwari, R., G. Panigrahi and Angappan, K. 2014. Molecular characterization of distinct YMV (Yellow mosaic virus) isolates affecting pulses in India with the aid of coat protein gene as a marker for identification. Mol. Biol. Rep. 41(4): 2635-2644.

Mandal, B., A., Varma and Malathi, V. G. 1997. Systemic infection of Vigna 
mungo using the cloned DNAs of the black gram isolate mungbean yellow mosaic geminivirus through agroinoculation and transmission of the progeny virus by whiteflies. J. Phytopathol. 145, 505-510.

Manjunatha, N., N. Haveri, B. A. Reddy, S. Archana and Hurakadli, M. S. 2001. Molecular detection and characterization of virus causing yellow mosaic disease of Redgram (Cajanus cajan L. Millsp) in Karnataka. Int. J. Pure App. Biosci. 3 (4): 258-264.

Mayo, M. A. and Pringle, C. R. 1998. Virus Taxonomy-1997. J. Gen. Virol. 79, 649657.

Nei, M. and Kumar, S. (2000). Molecular Evolution and Phylogenetics. Oxford University Press, New York.

Padidam M., R. N. Beachy and Fauquet, C. F. 1995. Classification and identification of geminiviruses using sequence comparisons. J. Gen. Virol. 76, 249263.

Pant, V., D. Gupta, N. R. Choudhury, V.G. Malathi, A. Varma and Mukherjee, S. K. 2001. Molecular characterization of the rep protein of the blackgram isolate of Indian mungbean yellow mosaic virus. J. Gen. Virol. 82, 2559-67.

Paximadis M. A. M., Idris, I. Torres-Jerez, A. Villarreal, M. E. C. Rey and Brown, J. K. 1998. Symptom phenotype, host range and molecular characterization of geminiviruses with a common tobacco host in the old and new world. Arch. Virol. 144, 703-717.

Prema, G. U. and Rangaswamy, K.T. 2018. Molecular detection and characterization of coat protein gene of mungbean yellow mosaic virus (MYMV) from Karnataka. Internat. J. Agric. Sci. 10(3): 5118-5122.

Ramesh, S. V., S. C. Bhagat, G. K. Gupta, S. M. Husain and Suresh, C. 2017. Genomic sequence characterization of Begomovirus infecting soybean and molecular evolutionary genomics of Legume yellow mosaic viruses (LYMVs). POJ 10 (02):88-96.

Shahakar, S. and Peter, A. 2015. Optimization of DNA isolation protocol from mungbean (Vigna radiata L. Wilczek). Mysore J. Agric. Sci. 49 (2): 247-249.

Thirumaran, A. S. and Seralathan, M. A. 1988. Utilization of mungbean. In: Shanmugasundaram S, McClean BT (eds) Proceedings of the second international mungbean symposium, Shanhua, Taiwan: The World Vegetable Center (AVRDC). Taiwan. pp. 470-485.

Usharani, K.S., B. Surendranath, Q. Haq and Malathi, V.G. 2004. Yellow mosaic virus infecting soybean in northern India is distinct from the species infecting soybean in southern and western India. Curr. Sci. 86, 845-850.

\section{How to cite this article:}

Swapnil Shahakar, Renuka and Anitha Pater. 2018. Molecular Characterization of Virus Strain Causing Yellow Mosaic Disease (YMD) in Mungbean (Vigna radiata L. Wilczek). Int.J.Curr.Microbiol.App.Sci. 7(10): 3727-3744. doi: https://doi.org/10.20546/ijcmas.2018.710.430 